\title{
Thematic Magazines: Alternative Method to Control Learning Outcomes of Future Foreign Language Teachers
}

\author{
Olga Mishchenko
}

Kharkiv Humanitarian Pedagogical Academy, Ukraine.

Email:olgamishchenko7@gmail.com

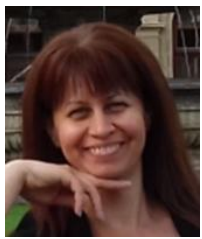

\begin{abstract}
In this article we identify the main functions (diagnostic, educational, upbringing), forms (frontal, group, individual, combined control and self-assessment) and principles of control (regularity, comprehensiveness, objectivity, individualization, purpose-focused and thematic), reveal the peculiarities of the thematic magazines as an alternative method to control learning outcomes of future foreign language teachers, describe the methodology of the use of thematic magazines in the educational process of the Academy. We also scrutinize the effectiveness of the use of the thematic magazines as an alternative method to control students' learning outcomes in the Practice of Spoken and Written English Language lessons at the Academy. Twenty three second year students have taken part in the study as participants. The method of Mathematical Statistics has been used to calculate the results. According to the findings the use of the thematic magazines is an effective alternative method to control students' outcomes which help to develop students' language skills and improve their creative abilities and intensify their interest in foreign language study.
\end{abstract}

Keywords: Thematic magazines, Control, Higher education, Future teachers, Foreign languages.

Citation | Olga Mishchenko (2019). Thematic Magazines: Foreign Languag to Control Learning Outcomes of Futine Research, 6(3): 116-121.

History:

Received: 14 March 2019

Revised: 18 April 2019

Accepted: 22 May 2019

Published: 5 August 2019

Licensed: This work is licensed under a Creative Commons

Attribution 3.0 License $(\mathrm{ccc})$ E

Publisher: Asian Online Journal Publishing Group
Funding: This study received no specific financial support.

Competing Interests: The author declares that there are no conflicts of interests regarding the publication of this paper.

Transparency: The author confirms that the manuscript is an honest, Transparency: The author confirms that the manuscript is an honest,
accurate, and transparent account of the study was reported; that no vital features of the study have been omitted; and that any discrepancies from the features of the study have been omitt
study as planned have been explained.

Ethical: This study follows all ethical practices during writing.

\section{Contents}

1. Introduction . 


\section{Contribution of this paper to the literature}

This study contributes to existing literature by identifying the main functions (diagnostic, educational, upbringing), forms (frontal, group, individual, combined control and self-assessment) and principles of control (regularity, comprehensiveness, objectivity, individualization, purpose-focused and thematic), reveal the peculiarities of the thematic magazines as an alternative method to control learning outcomes of future foreign language teachers, describe the methodology of the use of thematic magazines in the educational process of the Academy.

\section{Introduction}

The control of the level of knowledge, skills and abilities of students is an important and integral part of the successful command of a foreign language. Control is the ratio between the achieved results and the planned objectives of training. Correctly organized control of students' educational activity allows the teacher not only assess the level of students' acquisition of material, timely provide the necessary assistance, but also to see your own achievements and disadvantages in chosen teaching methods. All of these together create favorable conditions for the development of the students' cognitive abilities and to intensify their independent study. Therefore, choosing the form for controlling the quality of the acquired knowledge is extremely important.

The analysis of scientific and pedagogical sources proves that in recent years the interest of the Ukrainian and foreign scientists to the problems of the use of alternative methods to control students' learning outcomes in the educational process has considerably increased.

However, in the theory and practice of higher pedagogical education the problem of the implementation of the thematic magazines as the alternative method used to control learning outcomes of future foreign language teachers in higher educational institutions and its importance in the context of professional training hasn't been entirely examined.

\section{Theoretical Framework}

\subsection{Functions, Forms and Principles of Control}

Determining the level of the learning outcomes of future foreign language teachers is especially important in view of the fact that educational activity should ultimately not only facilitate the formulation of the amount of knowledge and skills, but also form students' competence as self-sufficiency for optimal actions.

Bakhanov (2008) reports that the improvement of students' educational activities control quality and an objective assessment of their knowledge are the important means of the educational process management. Since, for a pedagogically competent definition of the purpose of further education, it is necessary to see an objective picture of the level of assimilation of the educational material by students of the higher educational institutions.

Tarnopolsky (1989) claims control and self-assessment have to assist any educational activity. If control and assessment are built correctly, they contribute to the timely detection of gaps in students' knowledge and abilities, the revision and systematization of the material, the establishment of readiness for the acquisition of new material, the formation of the ability to use methods of self-assessment and control.

The structural components of control are identification and measurement (checking) and evaluation of students' learning outcomes. The control over learning outcomes of future foreign language teachers provides the feedback between a lecturer and students.

The analysis of scientific and methodical literature (Bachman, 1990; Molokovich, 2001; Baranovska and Koval, 2002; Pometun, 2002) allowed determining the basic functions of control: diagnostic, educational, corrective, prognostic, upbringing, developing, stimulating and motivational. When selecting these control functions as the main we took into account that 1) knowledge check gives a teacher the opportunity to determine the actual level of students' knowledge and to monitor the effectiveness of methods and techniques; 2) knowledge check is an integral part of the educational process, because it provides training, educational and upbringing goals; 3) when a teacher explains answers during knowledge check, it reveals to students specific opportunities of enhancing results of their academic achievements.

Let us examine the above mentioned functions of control of learning outcomes of future foreign language teachers in detail.

The diagnostic function of control is related to the definition of knowledge and skills' types, their qualitative characteristics, properties and levels of students' mastering in accordance with the objectives. It provides the opportunity for a teacher to identify gaps in students' knowledge and skills, to find out the causes of their occurrence and, accordingly, to adjust students' educational and cognitive activity and ways to manage it. The attention should be paid to the point there is a "correction", not "retraining" that in the control process. The obtained results of control are used to predict the ways of improving the teaching methods in general, foresee the level of its effectiveness in different conditions.

Educational function is aimed at developing such tasks for students, which promote generalization, deepening and systematization of knowledge and logical thinking development. The control is used to repeat and clarify the knowledge, prepare students for the new material perception. The knowledge control should be organized in such a way that it fulfills the educational function almost in all classes. While fulfilling the knowledge control in this way, not only individual students' knowledge is diagnosed, but also at the same time the knowledge of all students of the group is deepened. It activates the group, promotes the development of students' attention and gives the teacher the opportunity to evaluate more students' learning outcomes throughout the class.

Romashchenko (2012) reports that using control in the educational process helps to develop students' volition, attention, thinking, memory, speech, their cognitive activity and independence.

One of the most important tasks in the process of training future foreign language teachers is the development of the following skills such as mutual and self-assessment(mutual and self-assessment, mutual and self-evaluation), mutual and self-correction, which can be purposefully developed only in the control process (Todd, 2002).

The control fulfills the upbringing function. Properly organized control develops students' cognitive interest and stimulates them to work systematically and persistently, causes the development of important personality 
qualities such as responsibility, the ability to overcome difficulties and independence. Since, the results of individual efforts during the control become the subject of public discussion and evaluation. Assessment is one of the important means of motivating and stimulating students' educational and cognitive activity in the educational process. This function, in combination with other motifs of the study, fulfills, if the student's future prospect is formed, a positive emotional mood is created and maintained, the desire to learn is updated and an adequate selfimage is formed.

Depending on the specifics of the organizational forms we distinguish the frontal, group, individual, combined control and self-assessment (Pometun, 2002). During the frontal control a teacher asks questions on a small volume of material and a lot of students give short answers, usually from the place. This form of control allows combining successfully knowledge check with revision and consolidation the studied material. A teacher asks questions, as a rule, to the whole group of students so that all of them take part in the discussion of these questions. Each student can add, correct, clarify the answers of his classmates, give his own examples, etc. The frontal control often looks like a conversation. During the frontal control a large part of students' knowledge in a group can be checked in a relatively short time. However, when it comes to the frontal control it is difficult to ensure the accuracy and comprehensiveness of each student's knowledge check.

The group control is used in those cases when there is a need to check the students' educational activity outcomes or the process of its implementation by a part of the students who have received a certain group task. In this case, the questions are addressed to this group and the decision is taken by all students who worked in this group. Individual control is widely used to test the knowledge, skills and abilities of students. Control should stimulate the continuous work of all students. With proper organization, individual control is perceived by students as a normal element of the educational process and does not cause negative emotions. The individual control is designed to test a small number of students during a class. It depends on the time taken for the test, the nature and amount of the material that was studied and the students' level of preparation.

The combined control is a successful combination of the individual control with the front and group control. Students' self-assessment provides the functioning of internal feedback in the process of learning, obtaining information about the completeness and quality of studying the program material, the strength of the formed skills and abilities. Self-assessment has a great psychological value that stimulates learning.

It should be mentioned that the control of students' learning outcomes is identified with the didactic principles. The main among them are regularity, comprehensiveness, objectivity, individualization, purpose-focused and thematic (Molokovich, 2001). The regularity, as a control principle, is conditioned, firstly, by the didactic expediency of control at all stages of the educational process; and secondly, the need to control each student in every class, in connection with the students' psychological peculiarities of the development of their cognitive processes. The comprehensiveness principle involves determining the level of mastering the students' knowledge and skills by their basic parameters in accordance with the goals set in the educational process.

The objectivity principle involves the correct evaluation of students' knowledge and skills and assessment of this knowledge. Only an objective assessment gives students deep moral satisfaction and is an effective stimulating factor in learning. It has not only a great educational value but also an upbringing one.

The purpose-focused principle determines a definite approach to the selection of material to be tested, in accordance with the choice of forms and methods of test and evaluation of knowledge, learning outcomes, taking into account students' individual peculiarities.

The thematic control principle is provided by checking the knowledge of the basic concepts of each topic that students must learn. A student learns the material not only by a continuous flow, but by certain parts, which must be comprehended after an active perception, and then systematized in his memory. The memorization quality depends on a certain amount of revising the learned material and its practical application. Only after these psychological actions you can check the quality of understanding and memorization and start learning the next part of the material. The thematic control principle is of great importance, since the determination of the knowledge level of the part of the material enables the teacher to manage the process of assimilation.

\subsection{Thematic Magazines as Alternative Method of Control}

At the present stage of a foreign language teaching, a lot of attention is paid to the communicative, collaborative and creative orientation of educational activity. Therefore the usage of thematic magazines as an alternative method of the control of students' learning outcomes is an expedient and essential part of the educational process.

Under the "thematic magazine", we mean the electronic or printed version of a magazine created by a student on a given subject and has a clearly defined structure.

The essential elements of the thematic magazine is the title page, which is executed on the model of glossy magazines; the page of the editor where a student tells about himself and why this issue is dedicated to this topic; content in which all the components of the magazine are listed.

It should be noted that the creation of thematic magazines takes place in several stages:

- Preparatory stage;

- Creation of the magazine stage;

- Summing up stage.

Let us reveal the peculiarities of fulfilling of each of the specified stages.

The preparatory stage takes place in the first class which is devoted to a certain topic. It should be noted that depending on the number of students in the group and the level of their training, the work can be performed by one student, a couple or a creative group. At the preparatory stage students are given a topic, which the issue of their magazines will be devoted to. Students discuss the topic and express their ideas about what can be included in the issue. Together they form the contents of the magazine and decide how many sections will be there.

The unchanging sections of the magazine remain: the page of the editor or the creative group, which provides information about the members of the creative group or the editor, the relevance of the chosen topic of the magazine, entertainment pages (horoscope, test, news of the world of music and cinema, books reviews), and, if a 
print version is planned, two clean pages must be left for readers reviews. A number of thematic articles are chosen by the students themselves. The deadline for a magazine publishing is also set.

After completing the necessary preparatory work, students can immediately proceed to the creation of their thematic magazines. At the creation stage, the responsibilities of each member of the creative group are clearly formulated (each student chooses the section, he will be responsible for), the editor of the issue is chosen too. His job is to write the editor's page, the content and layout of the issue. Students search and select materials and design their pages on their own.

It is worth mentioning that at this stage, students enrich their vocabulary with new lexemes, which promotes not only the improvement of their foreign language competence, but also the development of their memory, attention and imagination.

After the thematic magazines are published, the final stage of working with them begins. Obviously this is a crucial stage of work as the control of the students' knowledge, skills and abilities is carried out here. Moreover, control is carried out not only by the teacher, but also by group members.

After reading the magazine, students should leave their comments, evaluating the magazine according to the following criteria:

- Whether the submitted material corresponds to the given topic;

- Whether all necessary sections are included in the magazine's contents;

- Whether it was convenient to read the magazine (technical design);

- What you liked the most in the magazine;

- Whether there were any disadvantages, if so, then give some advice on how the next issue can be improved.

The teacher's task is to check magazines for the presence of lexical-grammatical and stylistic mistakes both in the magazines' texts, as well as in the comments.

\section{Findings and Results}

We use magazines aiming to check the level of the development of students' language skills such as lexical and grammar skills; communicative skills, where the ability to use a foreign language in written communication is important; students' knowledge of essential vocabulary areas including collocations, idioms, phrasal verbs and fixed phrases.

Students' learning outcomes can be divided into four levels: low (receptive and productive); middle (reproductive); sufficient (constructive and differentiated); high (creative).

Each level can be characterized by the following criteria that determine the general approaches to identifying the level of students' academic achievements and establish relevance between the requirements for knowledge and skills and result indicator in marks according to the levels of academic achievements (Nikolayeva, 2003). The levels are presented in Table 1.

Table-1. Levels of students' academic achievements.

\begin{tabular}{|c|c|c|c|c|}
\hline \multicolumn{5}{|l|}{ Writing } \\
\hline \multirow[b]{2}{*}{$\begin{array}{l}\text { Level of academic } \\
\text { achievements }\end{array}$} & \multirow[b]{2}{*}{ Marks } & \multirow[b]{2}{*}{ Assessment criteria of students' academic achievements } & \multicolumn{2}{|c|}{ Literacy } \\
\hline & & & 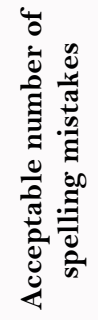 & 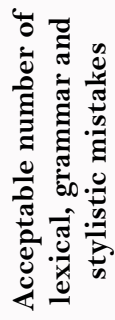 \\
\hline \multirow{3}{*}{ Low } & 1 & Student can write learnt words making a lot of spelling mistakes. & 8 & 9 \\
\hline & 2 & Student can write learnt words and word combinations. & 6 & 9 \\
\hline & 3 & $\begin{array}{l}\text { Student can write simple unextended sentences but the content is little } \\
\text { relevant. }\end{array}$ & 6 & 8 \\
\hline \multirow{3}{*}{ Middle } & 4 & $\begin{array}{l}\text { Student can write a letter using a model but use poor range of structures } \\
\text { and vocabulary making mistakes which impede text understanding. }\end{array}$ & 6 & 6 \\
\hline & 5 & $\begin{array}{l}\text { Student can write a short letter using a model. Language is simplistic; } \\
\text { linking of sentences is not maintained. }\end{array}$ & $4-5$ & 5 \\
\hline & 6 & $\begin{array}{l}\text { Student can write a short letter using a model. Linking of sentences is not } \\
\text { always maintained; poor range of structures and vocabulary. }\end{array}$ & $4-5$ & 5 \\
\hline \multirow[t]{3}{*}{ Sufficient } & 7 & $\begin{array}{l}\text { Student can write a short letter using a model. There are a number of } \\
\text { mistakes but they are mostly non-impeding. The text consists of idioms, } \\
\text { linking words, phrasal verbs etc. }\end{array}$ & 4 & 4 \\
\hline & 8 & $\begin{array}{l}\text { Student can write a short letter without using a model. There are several } \\
\text { mistakes but they are mostly non-impeding. The text consists of idioms, } \\
\text { linking words, phrasal verbs etc. }\end{array}$ & 3 & 3 \\
\hline & 9 & $\begin{array}{l}\text { Student can write a short letter. There are several spelling mistakes } \\
\text { generally non-impeding. The text consists of idioms, linking words, } \\
\text { phrasal verbs etc. }\end{array}$ & 3 & 2 \\
\hline \multirow[t]{2}{*}{ High } & 10 & $\begin{array}{l}\text { Student can write a letter giving his personal opinion and using more } \\
\text { than adequate range of structures and vocabulary within the task set. } \\
\text { There are several spelling mistakes generally non-impeding. The text } \\
\text { consists of idioms, linking words, phrasal verbs etc. }\end{array}$ & 2 & 1 \\
\hline & 11 & $\begin{array}{l}\text { Student can write a letter giving his personal opinion and using more } \\
\text { than adequate range of structures and vocabulary within the task set. The } \\
\text { text consists of idioms, linking words, phrasal verbs etc. }\end{array}$ & & \\
\hline
\end{tabular}

To check the effectiveness of the use of the thematic magazines as an alternative method to control learning outcomes of future foreign language teachers we decided to conduct the experiment in which 23 second year 
students of the foreign language department of Kharkiv Humanitarian Pedagogical Academy took part. The experiment held for one semester.

Before the experiment students were asked to write essays which were assessed by the criteria given in Table1.

The results of students' learning outcomes before using thematic magazines are presented in Table 2.They were calculated on the formulae (Sukodolsky, 1998): $\mathrm{n}=(\mathrm{K} \times 100 \%) / \mathrm{N}$, where

$\mathrm{n}-$ an indicator of a number of students in percentage terms with the same level of knowledge and skills;

$\mathrm{K}$ - a number of students with the definite level of academic achievements;

$\mathrm{N}-\mathrm{a}$ total number of students in a class.

\begin{tabular}{c|c|c|c|c}
\hline $\begin{array}{c}\text { Level of academic } \\
\text { achievements }\end{array}$ & High & Sufficient & Middle & Low \\
\hline results & $(4 \times 100 \%) / 23=17,4 \%$ & $(10 \times 100 \%) / 23=43,5 \%$ & $(5 \times 100 \%) / 23=21,7 \%$ & $(4 \times 100 \%) / 23=17,4 \%$ \\
\hline
\end{tabular}

Source: Research finding, 2019.

Results show significant variation in students' learning outcomes before using thematic magazines. These findings are shown in Figure 1.

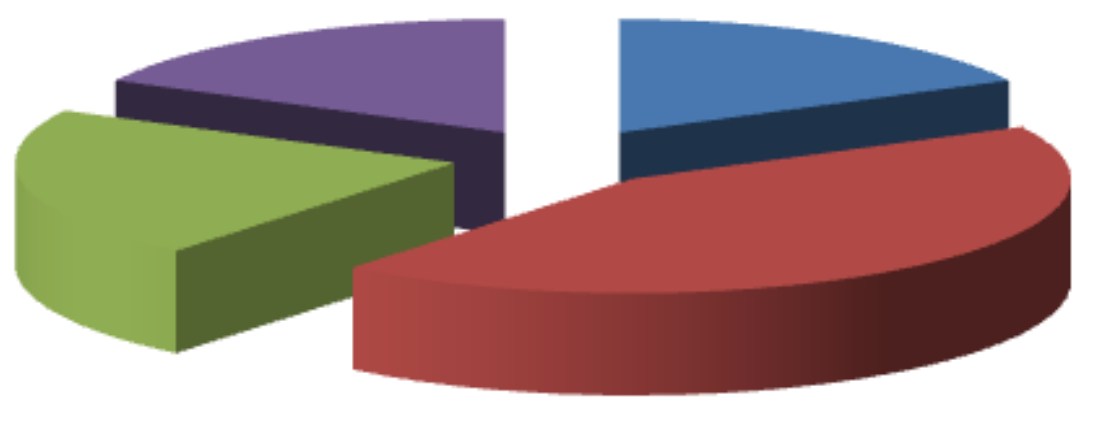

nigh

sufficient

middle

Figure-1. Students' learning outcomes before using thematic magazines.

Source: Research findings, 2019.

To determine the influence of the use of the thematic magazines on the development of students' language skills, it was necessary to identify and explain by a comparative analysis of qualitative and quantitative changes in students' learning outcomes which were obtained during the experimental research according to the selected criteria Table 1.

The results were again calculated on the formulae (Sukodolsky, 1998) $: \mathrm{n}=(\mathrm{K} \times 100 \%) / \mathrm{N}$, where

$\mathrm{n}-$ an indicator of a number of students in percentage terms with the same level of knowledge and skills;

$\mathrm{K}$ - a number of students with the definite level of academic achievements;

$\mathrm{N}-$ a total number of students in a class. 3.

The analysis of the results of students' learning outcomes after using thematic magazines is presented in Table

\begin{tabular}{c|c|c|c|c}
\multicolumn{5}{c|}{ Table-3. Students' learning outcomes after using thematic magazines } \\
\hline $\begin{array}{c}\text { Level of } \\
\text { academic } \\
\text { achievements }\end{array}$ & High & Sufficient & Middle & Low \\
\hline results & $(6 \times 100 \%) / 23=26 \%$ & $(11 \times 100 \%) / 23=48 \%$ & $(4 \times 100 \%) / 23=17,4 \%$ & $(2 \times 100 \%) / 23=8,6 \%$ \\
\hline
\end{tabular}

Source: Research findings, 2019.

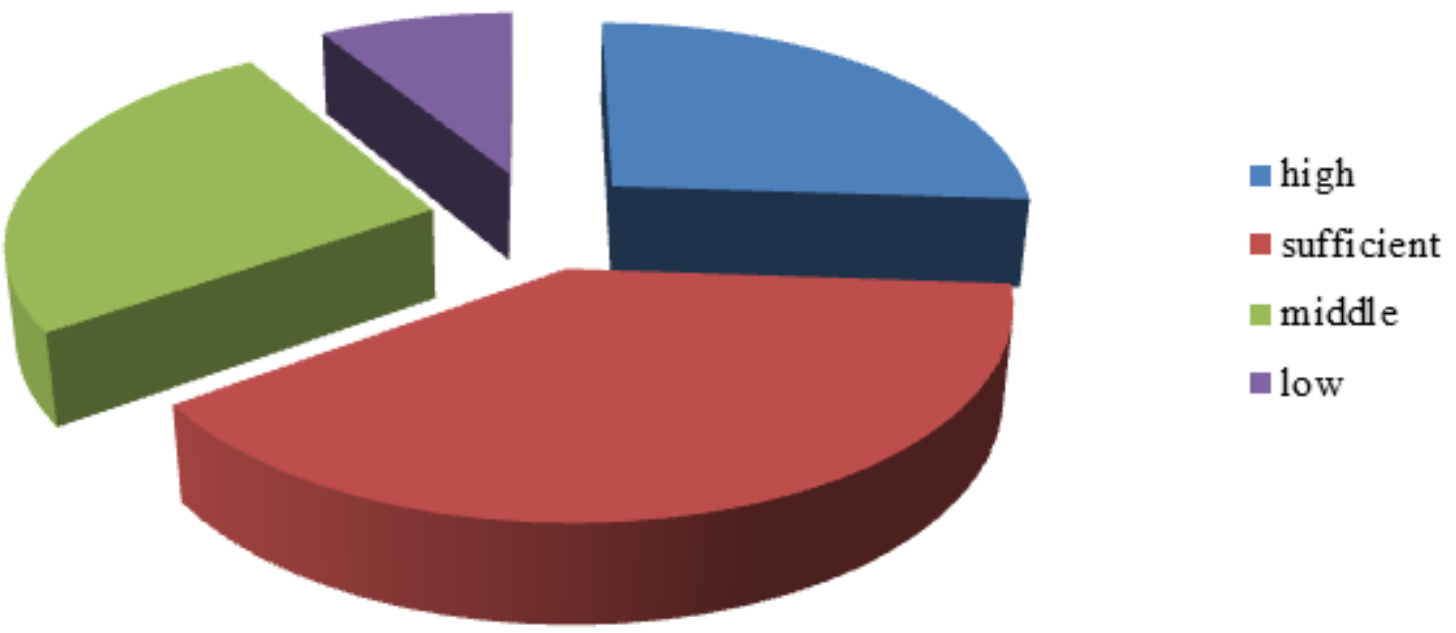

Source: Research findings, 2019.

Let us show the dynamic of changes in student's learning outcomes in Table 4. 
Table-4. Dynamic of changes in students' learning outcomes before and after using thematic magazines.

\begin{tabular}{c|c|c|c}
\hline Level of academic achievements & Before using thematic magazines & $\begin{array}{c}\text { After using thematic } \\
\text { magazines }\end{array}$ & \begin{tabular}{c} 
Changes \\
\hline High
\end{tabular} \\
\hline Sufficient & $17,4 \%$ & $26 \%$ & $+8,6 \%$ \\
\hline Middle & $43,5 \%$ & $48 \%$ & $4,5 \%$ \\
\hline Low & $21,7 \%$ & $17,4 \%$ & $-4,3 \%$ \\
\hline Source: Research findings, 2019. & $17,4 \%$ & $8,6 \%$ & $-8,8 \%$ \\
\hline
\end{tabular}

Source: Research findings, 2019.

To visualize the data which were obtained on the dynamics of changes in students' learning outcomes before and after using thematic magazines, we constructed a diagram Figure 3.

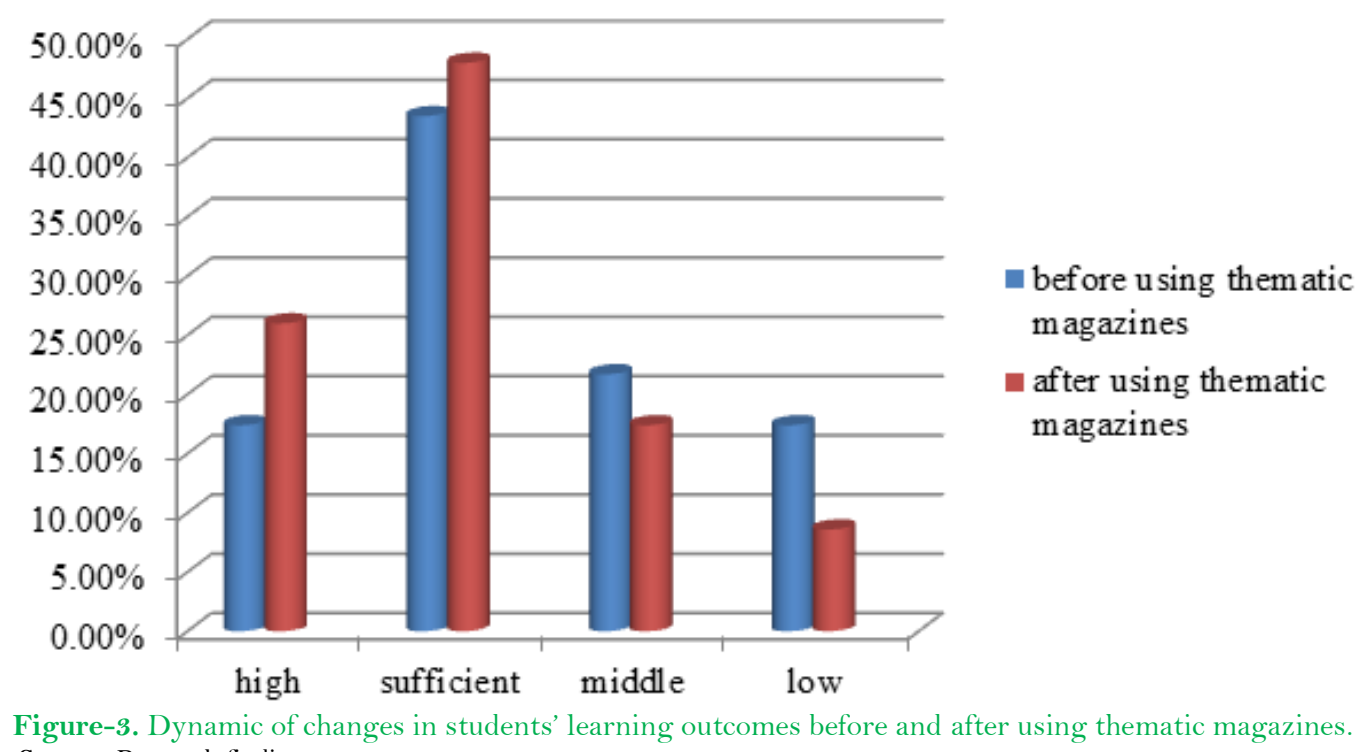

Figure-3. Dynamic of changes in students' learning outcomes before and after using thematic magazines. Source: Research findings, 2019.

\section{Conclusion}

Having analyzed the methodology of the use of thematic, we can conclude that the use of thematic magazines is an effective method to control learning outcomes of future foreign language teachers in classes on the practice of oral and written English language teaching in higher educational institutions as such a form of control meets the indicated didactic principles. This form of work proved to be not only an effective method of control, but also an effective method of learning activity that makes the process of learning English exciting, brings satisfaction; leads to the positive changes in the students' writing both in qualitative terms (the variety of speech unions), and in quantitative (language literacy, amount of expression); causes further desire to learn a foreign language and improve it; allows to get rid of students' fears to make mistakes and other negative emotions; and allows to intensify students' creative abilities in the process of their acquisition of social and cultural experience.

\section{References}

Bachman, L.F., 1990. Fundamental considerations in language testing. Oxford: Oxford University Press.

Bakhanov, K.O., 2008. Organization of person centered learning. Young history teacher adviser. Kharkiv: Osnova Publishing Group.

Baranovska, O. and L. Koval, 2002. Alternative systems for assessing students' academic outcomes in a person centered learning environment. Head master of School, Lyceum, Gymnasium: Scientific-Practical Journal, 6(1): $96-99$.

Molokovich, O.O., 2001. Testing speaking of the second year students studying English as a second foreign language. Thesis for a Candidate Degree by Speciality 13.00.02 - Theory and Methodology of Teaching. Kyiv: Kyiv National Linguistic University.

Nikolayeva, S.Y., 2003. European recommendations on language education: Studying, teaching, assessment. Kyiv: Lenvit Press Ltd. Pometun, O., 2002. How to assess learners' activities in interactive lessons. Scientific-Methodological Annals Doba, $2(1): 2-6$.

Romashchenko, I., 2012. Students' knowledge and skills control in higher educational institutions as a learning process managing instrument. Youth and Market, 2(85): 90-93.

Sukodolsky, G.V., 1998. Fundamentals of mathematical statistics for psychologists. St. Peterburg: St. Peterburg University Press.

Tarnopolsky, O.B., 1989. Methods of teaching foreign languages at technical university. Kyiv: High School Press Ltd.

Todd, R.W., 2002. Using self-assessment for evaluation. English Teaching Forum Magazine, 4O(1): 16 - 19. 